\title{
Preoperative Short-Course Radiotherapy in Locally Advanced Rectal Cancer: The Attitude on How to Use Radiotherapy in Rectal Cancer is Changing
}

\author{
Lars Påhlmann \\ Department of Surgery, University Hospital, Uppsala, Sweden
}

The article of Siegel and colleagues in this issue of ONKOLOGIE [1] is a very interesting contribution on assessing response to preoperative short-course radiotherapy in locally advanced rectal cancer by using FDG-PET scan. The whole attitude on to how to use radiotherapy in rectal cancer is slowly changing. It has been shown in studies that preoperative radiotherapy is much better than postoperative radiotherapy $[2,3]$ and it has also been demonstrated in a meta-analysis that, provided the dose is high enough, the effect on local recurrence is better if doses are given preoperatively rather than postoperatively [4]. The obvious next step in the treatment of rectal cancer is to give radiotherapy alone or chemoradiotherapy and delay the surgery. The question is of course for how long. In some of the patients, the response to radiation on the tumor is of such a magnitude that surgery can be postponed [5]. Subsequently there will be a therapeutic option for some patients similar to the treatment of anal carcinomas today. This certainly is of extreme interest in patients with very low rectal cancers where the alternative is abdominal perineal excision.

The main question is how to interpret the downsizing effect in vivo. The authors have now demonstrated the use of the FDGPET scan to demonstrate the effect on the tumor. This is very promising and hopefully this might be one of the jigsaw pieces which should be used to evaluate the effect of radiotherapy. Normal imaging with ultrasound and magnetic resonance imaging is difficult after radiotherapy and we will always find some thickening in the tumor area indicating problems with evaluating the total effect of radiotherapy. If FDG-PET scan is the new way to go, we will add that to our armamentarium in the decision-making of postponing surgery and put patients into a follow-up program instead of doing radical surgery. We know that 10 , perhaps $20 \%$ of our patients might be curable with radiotherapy or chemoradiotherapy alone. This is an interesting step forward in the clinical evaluation done by these authors.

\section{References}

1 Siegel R, Dresel S, Koswig S, Gebauer B, Hünerbein M, Schneider W, Schlag PM: Response to Preoperative Short-Course Radiotherapy in Locally Advanced Rectal Cancer: Value of ${ }^{18}$ F-Fluorodeoxyglucose-Positron Emission Tomography. Onkologie 2008;31: DOI: 10.1159/000118037.

-2 Påhlman L, Glimelius B: Pre- or postoperative radiotherapy in rectal and rectosigmoid carcinoma - report from a randomized multicentre trial. Ann Surg 1990;211:187-195.

3 Sauer R, Becker H, Hohenberger W. et al.: Preoperative versus postoperative chemoradiotherapy for rectal cancer. New Engl J Med 2004;351:1731-1740.

4 Colorectal Cancer Collaborative Group: Adjuvant radiotherapy for rectal cancer: a systematic overview of 8,507 patients from 22 randomised trials. Lancet 2001;358:1291-304.

5 Habr-Gama A, de Souza PM, Ribeiro U, et al.: Low rectal cancer: impact of radiation and chemotherapy on surgical treatment. Dis Colon Rectum 1998;41: 1087-1096.

\section{KARGER \\ (c) 2008 S. Karger GmbH, Freiburg \\ Fax +497614520714

